\title{
INTERNALIZED STIGMA AND PSYCHOSOCIAL CORRELATES IN CHINESE PEOPLE WITH SEVERE MENTAL ILLNESS
}

\author{
Min Yin, Zheng Li.
}

School of Nursing, Peking Union Medical College, Beijing, China

\section{Background and Aims}

The internalization of stigma leads to various negative consequences among people with severe mental illness (SMI). Determination of the internalized stigma level of patients and the affecting factors are important for developing interventions to reduce patients' internalized stigma levels. The study aims to examine the internalized stigma and the socio-demographic and psychosocial factors associated with it among people with SMI in mainland China.

\section{Materials and methods}

A cross-sectional study was conducted in a sample of 156 adults diagnosed with schizophrenia, bipolar disorder or schizoaffective disorder in a tertiary psychiatric hospital in Beijing. The participants were evaluated by the Chinese versions of the Internalized Stigma of Mental IIIness (ISMI), the Perceived Devaluation and Discrimination (PDD) Scale and the Medical Outcomes Study Social Support Survey (MOS-SSS). Correlation analysis and multiple linear regression analysis were used to explore the contributing factors to the internalized stigma.

\section{Results}

Overall, $23.7 \%$ of subjects had moderate-tohigh ISMI scores using a cut-off criterion (2.5 on a 1-4 scale) in this research sample. There was a positive correlation between the internalized stigma and the perceived discrimination $(r=0.436, P<0.001)$. Correlation between the internalized stigma and the social support was negative $(r=-0.426, P<0.001)$. Multiple regression analysis indicated that higher levels of internalized stigma were associated with lower family income $(P=0.011)$, lower social support $(P=0.008)$ and higher perceived discrimination $(P<0.001)$.

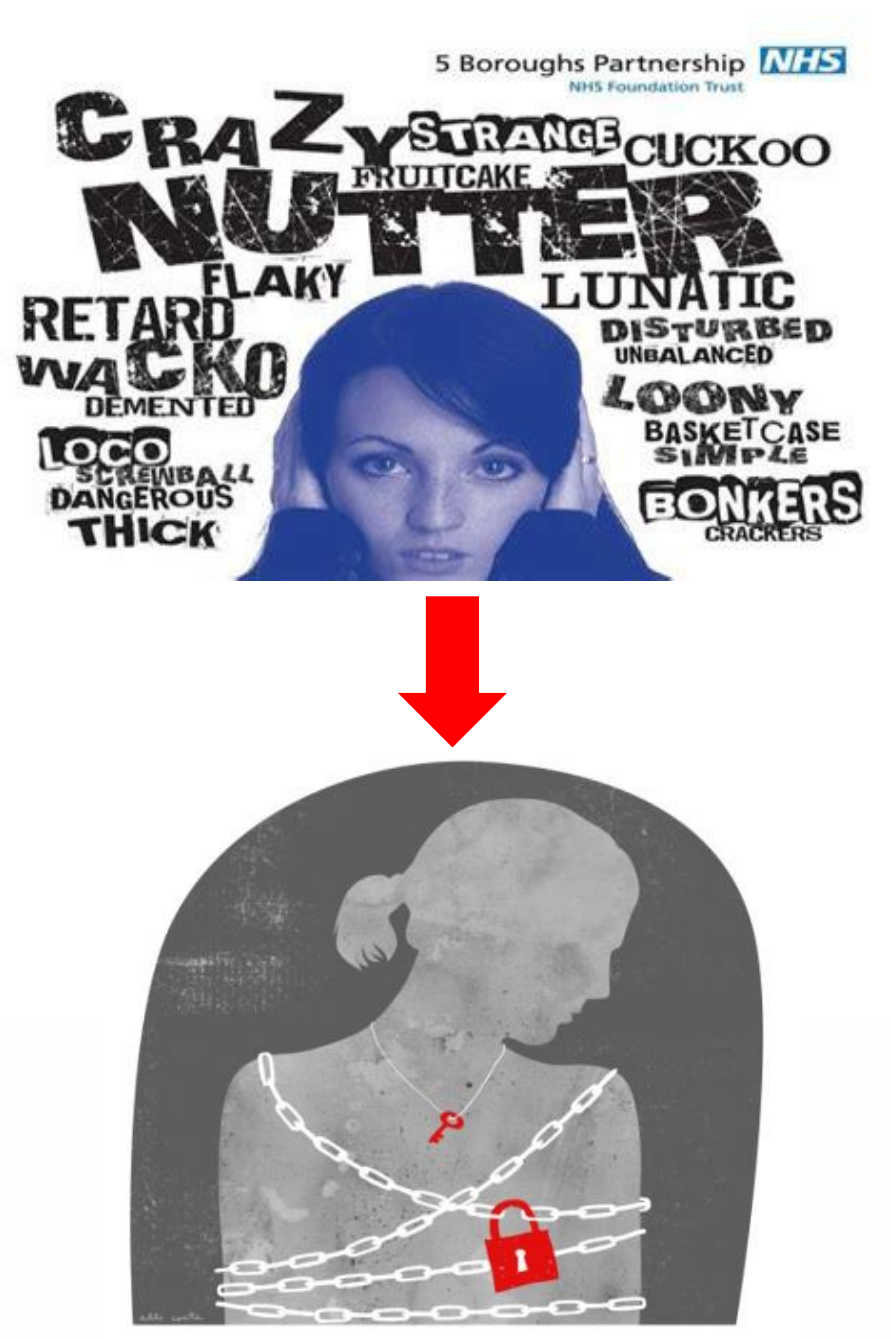

\section{Conclusions}

The research results indicated that family income, social support, and perceived discrimination were closely related to the internalized stigma of people with severe mental illness and these may be important factors considered for stigma interventions in the future. 